\title{
Standards not that standard
}

\author{
Cristina Vilanova ${ }^{1+}$, Kristie Tanner $^{1+}$, Pedro Dorado-Morales ${ }^{1}$, Paula Villaescusa ${ }^{1}$, Divya Chugani ${ }^{1}$, Alba Frías ${ }^{1}$, \\ Ernesto Segredo ${ }^{1}$, Xavier Molero ${ }^{1}$, Marco Fritschi ${ }^{1}$, Lucas Morales ${ }^{1}$, Daniel Ramón ${ }^{2}$, Carlos Peña ${ }^{3}$, Juli Peretó ${ }^{1,4}$ \\ and Manuel Porcar ${ }^{1,5^{*}}$
}

\begin{abstract}
There is a general assent on the key role of standards in Synthetic Biology. In two consecutive letters to this journal, suggestions on the assembly methods for the Registry of standard biological parts have been described. We fully agree with those authors on the need of a more flexible building strategy and we highlight in the present work two major functional challenges standardization efforts have to deal with: the need of both universal and orthogonal behaviors. We provide experimental data that clearly indicate that such engineering requirements should not be taken for granted in Synthetic Biology.
\end{abstract}

Keywords: Synthetic biology, Biobrick parts, Standardization, Orthogonality

\section{Letter to the editor}

Synthetic Biology, as an engineering approach to biotechnology, requires standard biological parts in order to overcome the limitations of assay-and-error strategies widely used in regular biotechnology. Indeed, tinkering may be sophisticated enough for successfully accomplishing simple genetic modifications, but metabolic engineering, let alone genome "programming", require a basic toolbox of reliable standard biological parts to be combined into progressively increasing levels of complexity. In two recent letters published in this journal, concerns on the constraints of the Registry of Standard Biological parts associated to the limitations of $3 \mathrm{~A}$ assembly methods have been highlighted $[1,2]$. The Registry is indeed a valuable tool for synthetic biologists as a comprehensive catalog of biological parts, which can be physically obtained from it, combined in silico with the aid of ad-hoc software tools (http://sbolstandard.org/), and finally assembled to yield complex biological circuits with, in principle, predictable behaviors. However, as an analysis of the use of the Registry by iGEM participants demonstrates, there is a surprisingly limited reuse of biological parts [3].

\footnotetext{
* Correspondence: manuel.porcar@uv.es

${ }^{\dagger}$ Equal contributors

${ }^{1}$ Institut Cavanilles de Biodiversitat i Biologia Evolutiva, Universitat de

València, C. Catedràtic José Beltrán 2, 46980 Paterna, Spain

${ }^{5}$ Fundació General de la Universitat de València, Valencia, Spain

Full list of author information is available at the end of the article
}

In the present letter, we want to contribute to this debate on the challenges of biological standards by critically revising engineering assumptions in $E$. coli bioengineering (http://2014.igem.org/Team:Valencia_Biocampus). Of those assumptions, there are two key concepts linked to standardization that are often incorrectly taken for granted: universality and orthogonality. The first notion refers to the standard behavior (when "standard" is used as an adjective it is usually synonymous to "universal"); in other words, biological parts are expected to display the same or very similar outputs independently of the biological system they are placed into. The second concept, orthogonality, relates to the independent behavior of biological parts.

We bench-tested these engineering pillars in the simplest scenarios: standardization was studied by introducing six DNA constructions (see Additional file 1: Table S1) built from commonly-used Biobrick parts in six different laboratory strains of $E$. coli and measuring their output under the same experimental conditions, whereas orthogonality was tested by co-transforming one of the strains (XL1-Blue) with a couple of these constructions (a green fluorescent protein placed under the control of a constitutive promoter, and a red fluorescent protein controlled by the same promoter) and measuring their output with flow cytometry techniques. Under our experimental conditions, significant differences in terms of expression levels were found among all the strains in five out of six constructions (Fig. 1) regardless the promoter type (constitutive or inducible) and the reporter protein 


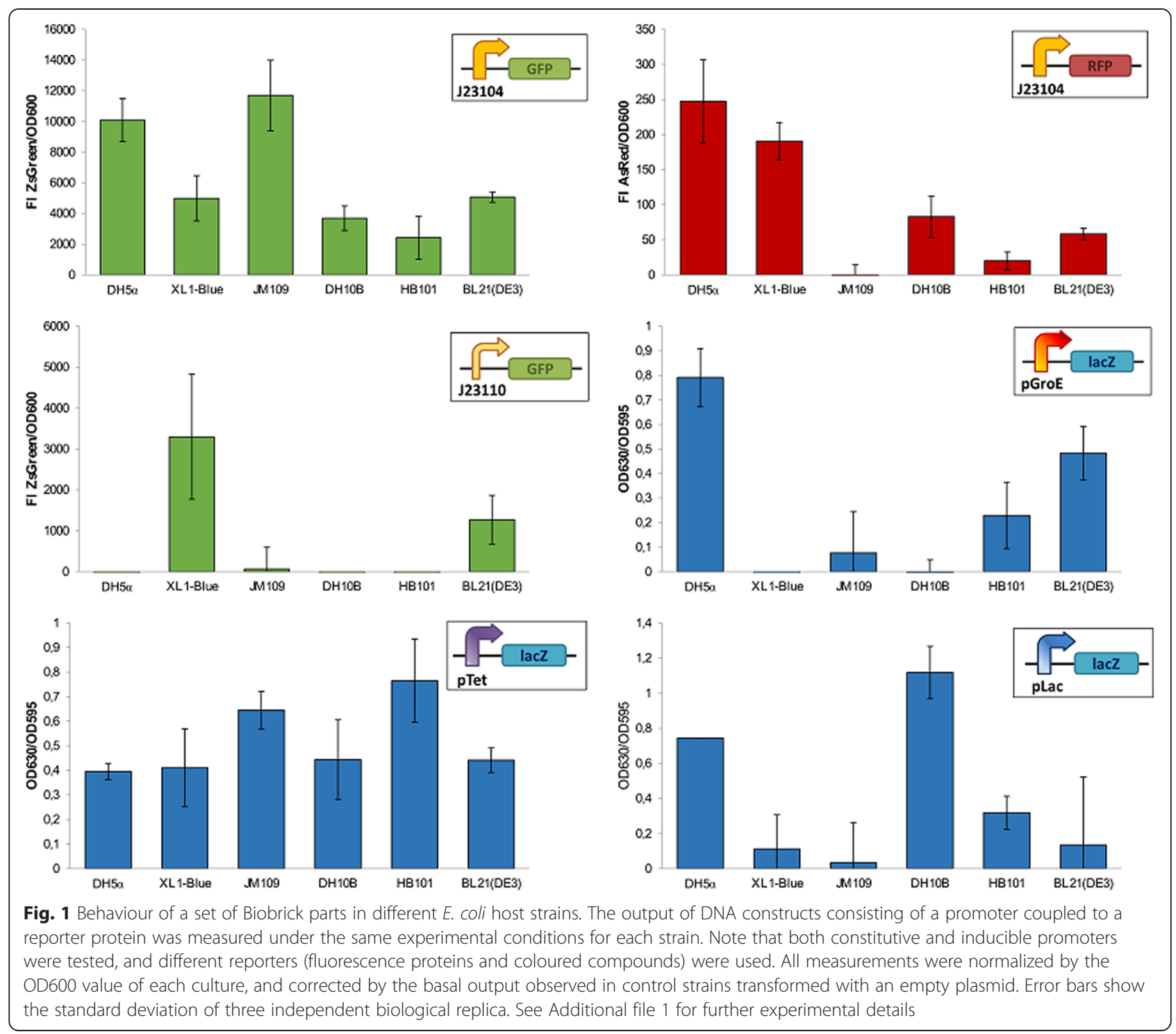

(fluorescent proteins or $\beta$-galactosidase), and double transformants did not exhibit a 1:1 red:green fluorescent phenotype (Fig. 2a). The lack of orthogonality of these two biological parts between them was in contrast with the stability of $E$. coli as a chassis, as we tested through a proteomics approach. Figure $2 \mathrm{~b}$ shows the proteomic profile of a transformed $E$. coli strain with a GFPcontaining plasmid and of two control strains (one nontransformed and one containing the empty plasmid), which reveals a minor impact of GFP and/or antibiotic resistance expression on the global bacterial proteomic architecture. E. coli is thus - at least in our conditions- a solid, orthogonal system respect to the heterologous protein expression shuttle it hosts.

The cellular phenomena underlying the lack of standard and orthogonal behavior of the Biobrick parts we tested might range from differences in protein maturation times
[4] and impact on biosynthetic burden [5] to context upstream and downstream sequences effects- dependencies [6] as well as to stochastic effects or intrinsic and extrinsic noise [7]; and references therein].

The fact that the tested genetic modifications proved weak standards in terms of universality and orthogonality does not necessarily imply the impossibility of engineering a particular strain in a predictable way, but it poses enormous difficulties in engineering strains on the basis of the work done on other strains, particularly taking into account that only a fraction of the genome is shared by all E. coli strains [8]. This suggests the need of a strain-by-strain both modelling and experimental previous effort. On the other hand, taking advantage of biological flexibility can be used in order to set up more robust devices, such as the use of bacterial haemoglobin to enhance production of foreign fluorescent proteins 
Vilanova et al. Journal of Biological Engineering (2015) 9:17

Page 3 of 4
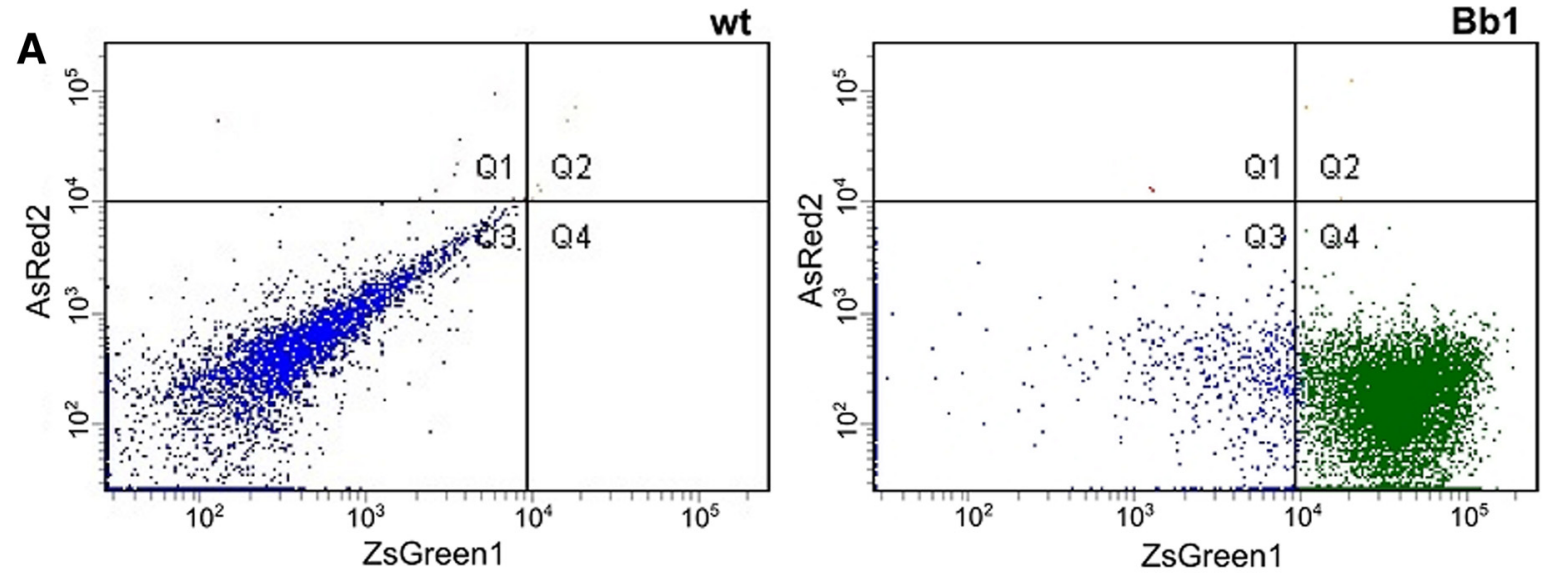

Bb

$\mathrm{Bb} 1+\mathrm{Bb} 2$
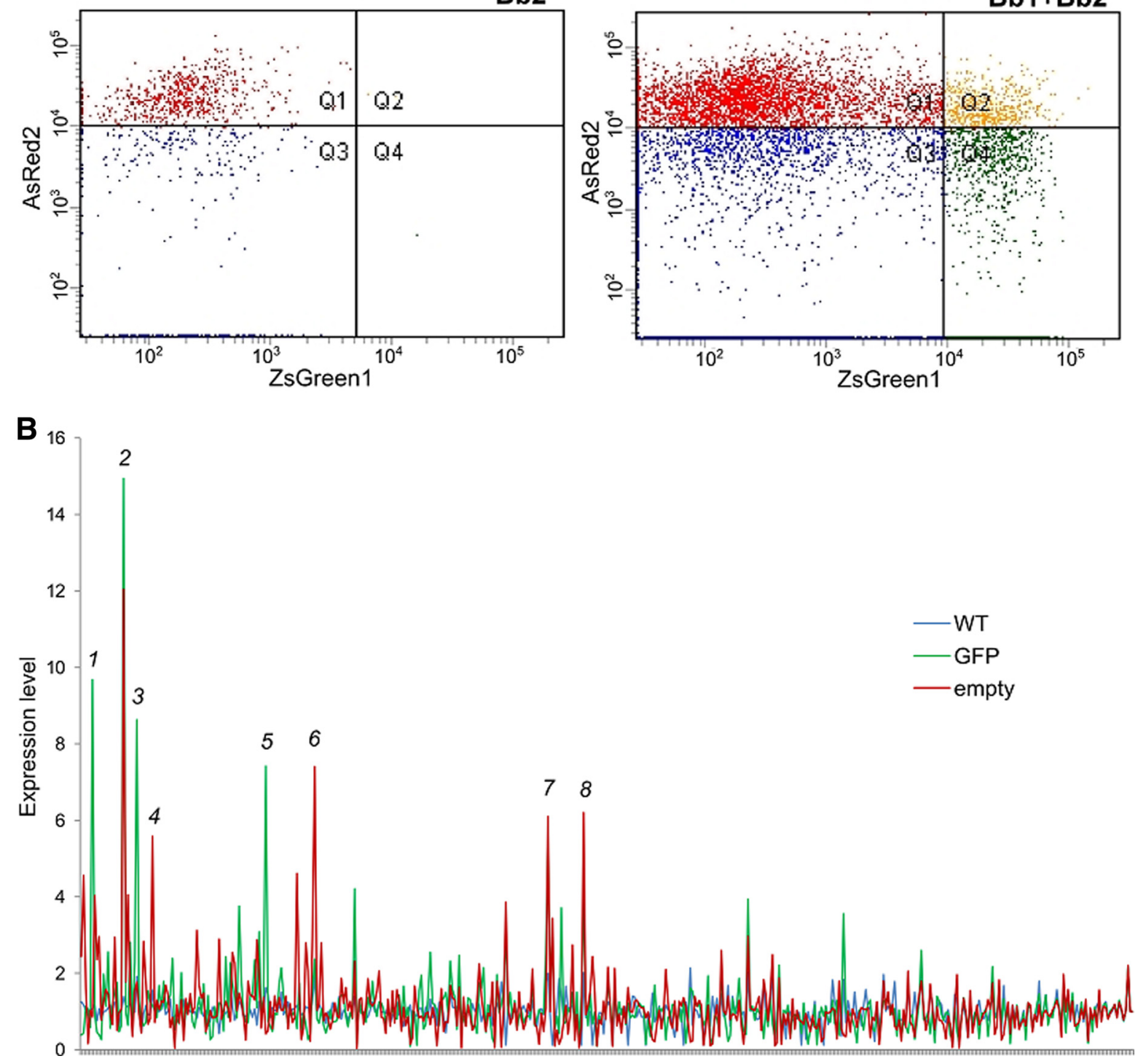

Fig. 2 (See legend on next page.) 
(See figure on previous page.)

Fig. 2 Orthogonality tests performed on a simple combination of two Biobrick parts. a Fluorescence output displayed by E. coli XL1 strain transformed with a single plasmid containing a constitutive promoter coupled to a green fluorescent protein (Bb1), a single plasmid containing the same promoter coupled to a red fluorescent protein (Bb2), and a combination of both plasmids. Plots showing flow cytometry measurements performed on individual cells (dots). $\mathbf{b}$ Comparison of the proteomic profile of an E. coli strain constitutively expressing a green fluorescent protein (green lines) with that of the same strain carrying an empty plasmid (red lines) and the control non-transformed strain (blue lines). Proteins showing a statistically significant change in expression are numbered according to Additional file 1: Table S2

[9], tuning intracellular physical distances between the regulator source and the target promoter for selecting a given level of noise in Synthetic Biology constructs [10], or designing synthetic constructs imposing a minimal burden to the host cells [5].

There is a general assent in the Synthetic Biology community on the need of collections of biological parts, in which engineering features (universality, stability, orthogonality, among others; [11]) should be checked and unambiguously quantified as a basic prerequisite for obtaining predictable and scalable designs. Systematic failures and difficulties to meet engineering standards might not constitute the most prized result in terms of publication purposes, but we strongly believe that a comprehensive view on the standardization failures of today is the strongest path towards the development of fully standard and orthogonal biological parts in the future.

\section{Additional file}

Additional file 1: Table S1. Biobrick parts (Bb1 to Bb6) included in the different DNA constructions tested in this work. Table S2. Proteins displaying statistically significant alterations in their expression levels, as detected by iTRAQ analysis (DOCX $18 \mathrm{~kb}$ ).

\section{Competing interests}

The authors declare that they have no competing interests.

\section{Authors' contributions}

MP conceived and coordinated the design of the study and supervised laboratory work. CV and KT performed the experiments related to orthogonality and proteomics, whereas PDM and AF performed the measurements related to standard behavior. PV and DC supported all the experimental work. ES, MF, XM, LM and CP contributed to data analysis. JP and DR technically supported this work and strongly participated in data interpretation and discussion. MP, CV and KT wrote the manuscript. All authors read and approved the final manuscript.

\section{Acknowledgements}

Valencia-Biocampus iGEM 2014 Team was supported by the European Projects ST-Flow and ERA-SynBio, Biopolis SL (Parc Científic de la Universitat de València) and the University of València through the International Excellence Campus and Col · legi Major Rector Peset. We are especially indebted to Rafael García-Martínez (OPEX, Oficina per a les Polítiques d'Excel. lència, Universitat de València) and Soledat Rubio (Càtedra de Divulgació de la Ciència de la Universitat de València) for their constant encouragement and support. We also thank the proteomics service (SCSIE) of the Universitat de València for their technical support. CV is a recipient of a FPU fellowship from the MECD Spanish Ministry.

\section{Author details}

'Institut Cavanilles de Biodiversitat i Biologia Evolutiva, Universitat de València, C. Catedràtic José Beltrán 2, 46980 Paterna, Spain. ${ }^{2}$ Biopolis S.L, Parc Cientific Universitat de València, Paterna, Valencia, Spain. ${ }^{3}$ Instituto de Física Corpuscular (IFIC), CSIC - Universitat de València, Burjassot 46100, Spain. ${ }^{4}$ Departament de Bioquímica i Biologia Molecular, Universitat de València, Burjassot 46100, Spain. ${ }^{5}$ Fundació General de la Universitat de València, Valencia, Spain.

Received: 6 August 2015 Accepted: 16 September 2015

Published online: 01 October 2015

\section{References}

1. Alnahhas RN, Slater B, Huang Y, Mortensen C, Monk JW, Okasheh Y, et al. The case for decoupling assembly and submission standards to maintain a more flexible registry of biological parts. J Biol Eng. 2014;8:28.

2. Azizi A, Lam W, Phenix H, Tepliakova L, Roney IJ, Jedrysiak D, et al. No training required: experimental tests support homology-based DNA assembly as a best practice in synthetic biology. J Biol Eng. 2015;9:8.

3. Vilanova C, Porcar M. iGEM 2.0-refoundations for engineering biology. Nat Biotechnol. 2014;32:420-4.

4. Hebisch E, Knebel J, Landsberg J, Frey E, Leisner M. High variation of fluorescence protein maturation times in closely related Escherichia coli strains. PLoS One. 2013;8:e75991.

5. Ceroni F, Algar R, Stan G-B, Ellis T. Quantifying cellular capacity identifies gene expression designs with reduced burden. Nat Methods. 2015;12:415-8.

6. Pasotti L, Politi N, Zucca S, Cusella De Angelis MG, Magni P. Bottom-up engineering of biological systems through standard bricks: a modularity study on basic parts and devices. PLoS One. 2012;7:e39407.

7. Viney M, Reece SE. Adaptive noise. Proc R Soc B. 2013;280:20131104. doi:10.1098/rspb.2013.1104

8. Lukjancenko O, Wassenaar TM, Ussery DW. Comparison of 61 sequenced Escherichia coli genomes. Microb Ecol. 2010;60:708-20.

9. Kang DG, Kim YK, Cha HJ. Comparison of green fluorescent protein expression in two industrial Escherichia coli strains, BL21 and W3110, under co-expression of bacterial hemoglobin. Appl Microbiol Biotechnol. 2002;59:523-8.

10. Goñi-Moreno A, Benedetti I, Kim J, de Lorenzo V: Deconvolution of Gene Expression Noise into Physical Dynamics of Cognate Promoters. bioRxiv doi: http://dx.doi.org/10.1101/019927

11. Lucks JB, Qi L, Whitaker WR, Arkin AP. Toward scalable parts families for predictable design of biological circuits. Curr Opin Microbiol. 2008;11:567-73.

\section{Submit your next manuscript to BioMed Central and take full advantage of:}

- Convenient online submission

- Thorough peer review

- No space constraints or color figure charges

- Immediate publication on acceptance

- Inclusion in PubMed, CAS, Scopus and Google Scholar

- Research which is freely available for redistribution 